\title{
Editorials
}

\section{Integrating acute services for children and young people across primary and secondary care}

\section{DELIVERING INTEGRATED CARE: WHY FOCUS ON CHILDREN?}

We are guilty of many errors and many faults, but our worst crime is abandoning the children, neglecting the fountain of life. Many of the things we need can wait. The child cannot. Right now is the time his bones are being formed, his blood is being made, and his senses are being developed. To him we cannot answer, "Tomorrow", his name is today.' Gabriela Mistral, Nobel Laureate.

This poem delivers a powerful message; children are the future. Much of the current paediatric focus in The NHS Long Term Plan ${ }^{2}$ relates to public health initiatives such as tackling obesity and ensuring emotional wellbeing; benefits that will take years or decades to realise. While these should not be forgotten, acute services for children and young people (CYP) are rarely prioritised when new models of care are considered, especially when the older population accounts for over $75 \%$ of $\mathrm{NHS}$ spending. ${ }^{2,3}$ What reason is there for commissioners and clinical leaders to focus on improving non-elective services for CYP when the needs of the frail and older population are so pressing?

CYP under 18 years of age currently account for approximately $25 \%$ of attendances to primary and secondary care but $<12 \%$ of non-elective hospital admissions. ${ }^{4,5}$ The fact that children are the most likely age group to attend emergency departments unnecessarily suggests that high levels of parental anxiety is driving health-seeking behaviour. ${ }^{7}$ This observation justifies initiatives to deliver integrated acute services for CYP that achieve consistency across primary and secondary care. Consistent management and safety netting by healthcare professionals reduces parental anxiety, which in turn reduces urgent care presentations by empowering parents to confidently selfmanage minor illnesses. ${ }^{8,9}$ Addressing this avoidable activity would relieve pressure on our currently overstretched urgent care services, improving access and quality of care to those who need it most.

\section{THE CONNECTING CARE CHILDREN'S HUB MODEL}

The Connecting Care Children's Hub (CCCH) model in Hampshire and the Isle of Wight (HIOW) has drawn on ideas from similar models successfully implemented in North West London (Connecting Care For
Children [CC4C]) and the Evelina Children's Hospital (Children and Young People's Health Partnership), in Taunton, Somerset. ${ }^{10}$ The model is centred within Primary Care Networks (PCNs). A consultant paediatrician is linked with a group of GP practices and associated staff. Together they deliver the core elements: (i) specialist outreach, involving a secondary care paediatrician joining a GP for monthly clinics; (ii) open access, providing PCN health professionals with access to a link secondary care paediatrician who can provide advice and support through monthly multidisciplinary team meetings (MTDs), and informally via email and telephone: and (iii) public and patient engagement through providing patient, parent, and family education.

The model aims to reduce urgent care activity in both primary and secondary care settings through education, support, and collaborative working. The CC4C pilot in North West London had a significant impact on urgent care activity, including a $39 \%$ reduction in outpatient referrals, 22\% reduction in presentations to the emergency department (ED), and a 17\% reduction in acute hospital admissions. The model also received extremely positive feedback from patients, families, and professionals. ${ }^{10}$ However, the ultimate aim of this model is to improve the health and wellbeing of CYP through strengthening relationships between primary and secondary care.

\section{THE HAMPSHIRE AND ISLE OF WIGHT PILOT}

In October 2017, NHS England awarded funding for a pilot of the $\mathrm{CCCH}$ model within HIOW. Implementation of twelve $\mathrm{CCCHs}$ across eight care commissioning groups for a 6-month period was planned. Due to a tight timeline for implementation, initial hubs were based in areas with strong local leadership, interest, and enthusiasm rather than population needs.

Local ownership and bespoke design of each of the $\mathrm{CCCHs}$ was prioritised within the HIOW pilot, with each hub determining the detail of how it would run, timings, location, and case-mix of patients. Common to all hubs, and we would suggest a crucial element for success, was a monthly MDT meeting held within primary care, in which community-based healthcare professionals from any practice within the hub were invited to bring clinical cases to discuss alongside a secondary care general paediatrician. MDT attendees included GPs, health visitors, practice nurses, dieticians, community paediatricians, staff from the child and adolescent mental health service, student practitioners, and social prescribers. The patients discussed included frequent attenders to primary care or the ED, those who might ordinarily be referred to outpatient clinics, and those where a multiprofessional approach to management was required. Aligned to this was a monthly joint clinic, held within primary care, in which a GP and general paediatrician reviewed patients together. These patients were referred directly to this clinic from GPs within the hub practices seeking a consultant paediatric opinion, or from the MDT meeting.

\section{OUTCOMES}

Analysis of patients seen within $\mathrm{CCCH}$ clinics or discussed in MDT meetings $(n=329)$ demonstrated a significant reduction in access to urgent care at 6 months postintervention, including a 35\% reduction in their attendance to the ED and a 58\% reduction in hospital admissions. Additionally, $\mathrm{CCCHs}$ are likely to have an impact beyond the specific children discussed within the MDT or seen in the clinic, as learning is spread to future similar cases. However, this practice level impact is likely to take time to materialise. Encouragingly, practice level data from one $\mathrm{CCCH}$, which has been running a full fidelity model since April 2018, has shown a $13 \%$ reduction in GP appointments for CYP between quarter 3 2017/2018 and quarter 3 2018/2019, compared to a 6.7\% reduction for children aged $0-18$ years across HIOW over the same time period. Data from this same PCN also show a $20 \%$ reduction in first paediatric outpatient appointments, a $7 \%$ reduction in non-elective paediatric admissions, and a $3 \%$ reduction in ED attendance over this time period.

Qualitative feedback from families and professionals involved in the pilot was extremely positive; parents felt more empowered to confidently manage selflimiting illness and staff valued access to workplace-based multiprofessional education as well as collaboration between primary, community, and secondary care professionals. Of the families seen within a $\mathrm{CCCH}$ clinic, $98 \%$ would recommend the service to family and friends. Of professionals attending $\mathrm{CCCH}$ MDT meetings, 93\% 
would recommend the meetings to their colleagues, and $88 \%$ indicated that they are likely to use learning from the MDT in their clinical practice. Specific feedback from professionals suggested that $\mathrm{CCCHs}$ have helped to break the physical barrier between primary and secondary care, benefiting both professionals and patients.

\section{THE CHALLENGES}

Despite strong and robust evidence of the impact of the CC4C model in North West London; there have been significant challenges and barriers to implementing them across HIOW. Of the twelve hubs, only six were successfully piloted; the main reason for failure being the then lack of suitable infrastructure within the emerging PCNs, especially in terms of identifying a driving force within primary care to keep practices engaged with the $\mathrm{CCCHs}$. Even the successful hubs were not without their own challenges; primary care staff are already under a huge amount of pressure and one of the biggest challenges was the capacity for staff to attend MDT meetings and clinics. Unlike in London, some of the HIOW hubs cover a large geographical area, and it was therefore challenging for professionals to attend meetings outside of their own practice. Geography was not the only barrier; each hub consisted of multiple individual practices often with different IT systems, which presented issues with information governance and data sharing. A further challenge was a lack of administrative support to support the MDT; including arranging dates and ensuring staff are invited, compilation of a list of frequent attendees to primary care and ED, booking patients into the clinic, and subsequently disseminating learning to all staff within the hub practices.

\section{TIME TO ACT}

Children are not currently seen as a priority when commissioners and clinical leaders look to deliver integrated urgent care. We have demonstrated that if clinical leaders invest time into implementing $\mathrm{CCCHs}$; they can reap benefits for both patients and healthcare professionals. The model also offers the potential to deliver communitybased training in child health as part of GP training and as part of paediatric training. The impact of $\mathrm{CCCHs}$ is likely to be greatest in areas of socioeconomic deprivation, where rates of urgent care activity for CYP are highest; ${ }^{11}$ we suggest a data-driven approach to deciding where to implement CCCHs. However, one must be mindful of the challenges faced when introducing novel services; most notably the scepticism that many frontline clinicians feel when asked to embrace new initiatives, many of which have little or no evidence to support them. We hope that the robust outcome data collected during this pilot will help to get buy-in from PCN health professions to facilitate successful roll-out of this model to other sites. Some of the other issues are likely to be overcome as PCNs mature; many of the successful pilot sites had the support of a local GP Federation or were based within a single 'super-practice PCN.

The $\mathrm{CCCH}$ model is just one example of innovative approaches to delivering integrated services for CYP. ${ }^{12}$ Yet they all share one key objective; to rebuild the precious relationship between community, primary, and secondary care-based colleagues that has been eroded over the past 20 years following round after round of service reconfiguration. Successful implementation relies on clinical leaders being supported to drive forward such initiatives, and for bodies such as the Royal College of General Practitioners and the Royal College of Paediatrics and Child Health to collaborate on training the future workforce to deliver integrated care. Now is the time to act.

\section{Sanjay Patel,}

Consultant Paediatrician, University Hospital Southampton NHS Foundation Trust, Southampton; Project Lead, Healthier Together; Clinical Lead, Children's Programme, Hampshire and Isle of Wight Sustainability and Transformation Partnership.

\section{Tamali Hodgkinson}

Paediatric Trainee and Education Fellow, University Hospital Southampton NHS Foundation Trust, Southampton.

\section{Roland Fowler,}

GP, North Baddesley Surgery, Hampshire; Medical Director, Tri Locality Care Ltd; Clinical Director for Children and Families, West Hampshire Care Commissioning Group.

\section{Kate Pryde,}

Consultant Paediatrician and Quality Improvement Lead, University Hospital Southampton NHS Foundation Trust, Southampton.

\section{Roisin Ward,}

GP, Clift Surgery, Hampshire.

\section{Provenance}

Freely submitted; not externally peer reviewed.

\section{Competing interests}

The authors have declared no competing interests.

DOI: https://doi.org/10.3399/bjgp20X708917

\section{ADDRESS FOR CORRESPONDENCE}

\section{Sanjay Patel}

Mailpoint 43, University Hospital Southampton NHS Foundation Trust, Tremona Road, Southampton S016 6YD, UK.

\section{Email: sanjay.pateldauhs.nhs.uk}

\section{REFERENCES}

1. Quoterati. Gabriela Mistral Quotes. https:// quoterati.com/authors/gabriela-mistral (accessed 27 Feb 2020).

2. NHS Digital. The NHS Long Term Plan. 2019 https://www.longtermplan.nhs.uk/wp-content/ uploads/2019/08/nhs-long-term-plan-version1.2.pdf (accessed 06 Mar 2020).

3. Licchetta M, Stelmach M. Office for Budget Responsibility. Fiscal sustainability analytical paper. Fiscal sustainability and public spending on health. 2016. http://obr.uk/docs/dlm uploads/Health-FSAP.pdf laccessed $06 \overline{\mathrm{Mar}}$ 2020).

4. NHS England. Hospital accident and emergency activity, 2017-18. 2018. https:// digital.nhs.uk/data-and-information/ publications/statistical/hospital-accident-emergency-activity/2017-18 laccessed 27 Feb 2020).

5. NHS Digital. Hospital admitted patient care activity, 2017-18. 2018. https://digital.nhs.uk/ data-and-information/publications/statistical/ hospital-admitted-patient-care-activity/2017-18 laccessed 27 Feb 2020).

6. McHale P. Wood S, Hughes $\mathrm{K}$, et al. Who uses emergency departments inappropriately and when - a national cross-sectional study using a monitoring data system. BMC Med 2013; 11: 258

7. Cabral C. Lucas PJ, Ingram J, et al. "It's safer to ..." parent consulting and clinician antibiotic prescribing decisions for children with respiratory tract infections: an analysis across four qualitative studies. Soc Sci Med 2015; 136-137: 156-164.

8. Francis NA, Butler CC, Hood K, et al. Effect of using an interactive booklet about childhood respiratory tract infections in primary care consultations on reconsulting and antibiotic prescribing: a cluster randomised controlled trial. BMJ 2009; 339: b2885.

9. Fake E, Lees A, Tapson K, Patel S. Parental views on the management of young children with respiratory tract infections in primary care - a pilot study. SelfCare 2018; 9(4): 23-34.

10. Montgomery-Taylor S, Watson M, Klaber R. Child Health General Practice Hubs: a service evaluation. Arch Dis Child 2016; 101(4): 333337

11. Kossarova L, Cheung R, Hargreaves D, Keeble E. Briefing. Admissions of inequality: emergency hospital use for children and young people. 2017. https://www.nuffieldtrust.org.uk/ files/2017-12/nt-admissions-of-inequality-web. pdf (accessed 06 Mar 2020).

12. Royal College of Paediatrics and Child Health. ICS and STP strategic plans recommendations. 2019. https://www.rcpch. ac.uk/sites/default/files/generated-pdf/ document/ICS-and-STP-strategic-plans--recommendations.pdf (accessed 06 Mar 2020). 